\title{
Dynamic morphological changes in Libman-Sacks endocarditis under different anticoagulation regimens
}

\author{
Takaya Kitano, ${ }^{1}$ Kaoruko Sengoku, ${ }^{2}$ Eri Itotagawa, ${ }^{3}$ Kenichi Todo ${ }^{1}$
}

${ }^{1}$ Neurology, Osaka University Graduate School of Medicine, Suita, Osaka, Japan

${ }^{2}$ Cardiovascular Medicine, Osaka University Graduate School of Medicine, Suita, Osaka, Japan ${ }^{3}$ Respiratory Medicine and Clinical Immunology, Osaka University Graduate School of Medicine, Suita, Osaka, Japan

\section{Correspondence to}

Dr Takaya Kitano,

takayakitano@neurol.med. osaka-u.ac.jp

Accepted 13 March 2019

\section{DESCRIPTION}

Libman-Sacks endocarditis is a prevalent complication in patients with systemic lupus erythematosus or antiphospholipid syndrome (APS). ${ }^{1}$ Although antithrombotic therapy can prevent thromboembolic events in APS, the optimal anticoagulation regimen remains uncertain. Here, we present a case of Libman-Sacks endocarditis and APS that showed drastic changes in endocardial vegetation morphology under different anticoagulation regimens.

A 51-year-old woman with a 10 -year history of systemic lupus erythematosus was admitted to our hospital with dizziness and right-sided ataxia. She had developed a flare of lupus nephritis months prior to presentation and received prednisone $20 \mathrm{mg}$ /day. She had no history of injection drug use. She had a history of atrial fibrillation without anticoagulation. Urinalysis revealed proteinuria of $2.8 \mathrm{~g} /$ day on admission. Lupus anticoagulant, anticardiolipin and anti- $\beta 2$-glycoprotein I antibodies were present according to the serum analysis. This finding was compatible with secondary APS. Brain
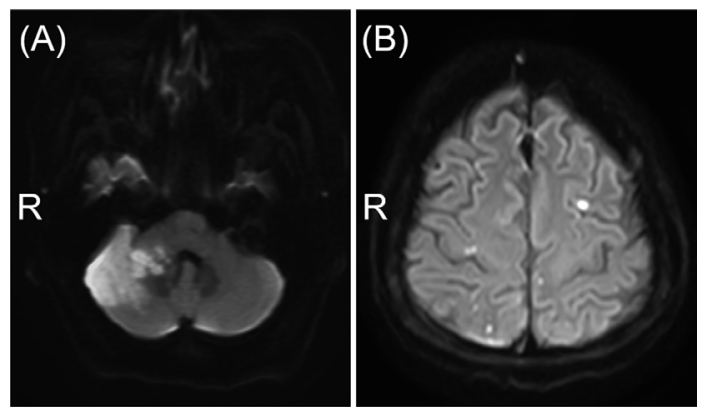

Figure 1 Diffusion-weighted MR images on admission (A) and on day 23 (B).
MRI revealed an acute right cerebellar infarction (figure 1A). No stenosis or occlusion was found in the intracranial arteries. Transoesophageal echocardiography (TEE) on admission revealed thickening of the mitral valve, but no abnormality in the aortic valve (figure 2A). A diagnosis of cardioembolic stroke attributable to atrial fibrillation was made, and apixaban $5 \mathrm{mg}$ twice daily was initiated.

Although no neurological deterioration was observed, follow-up MRI on day 23 revealed acute cerebral infarctions in multiple vascular territories (figure 1B). Repeated TEE on day 25 revealed a newly developed vegetation in the aortic valve (figure 2B). Blood cultures were negative; she was afebrile and had no skin or eye lesions. The predisposing heart condition was not present. Thus, infective endocarditis was unlikely. Valve abnormalities and positivity for antiphospholipid antibodies suggested Libman-Sacks endocarditis. Apixaban was ineffective and switched to continuous heparin infusion. The vegetation diminished within a week of initiation of heparin therapy (figure 2C). She had no signs of systemic embolism. After 2 weeks, heparin was switched to warfarin. Prednisone was increased to $50 \mathrm{mg} / \mathrm{day}$ and mycophenolate mofetil was added to treat lupus nephritis as proteinuria greater than $2 \mathrm{~g} /$ day persisted. Follow-up MRI revealed no recurrent stroke. The vegetation disappeared on day 75 (figure 2D).

The vegetations in Libman-Sacks endocarditis are sterile abnormal growths of tissue around the valves with autoimmune inflammation and thrombotic pathogenesis. ${ }^{1}$ The natural history and optimal treatment of Libman-Sacks endocarditis have not been fully elucidated, but some valvular abnormalities respond to anticoagulation therapy. ${ }^{2}$ In the
Check for updates

(C) BMJ Publishing Group Limited 2019. No commercial re-use. See rights and permissions. Published by BMJ.

To cite: Kitano T, Sengoku K, Itotagawa $\mathrm{E}$, et al. BMJ Case Rep 2019;12:e229909. doi:10.1136/bcr-2019229909
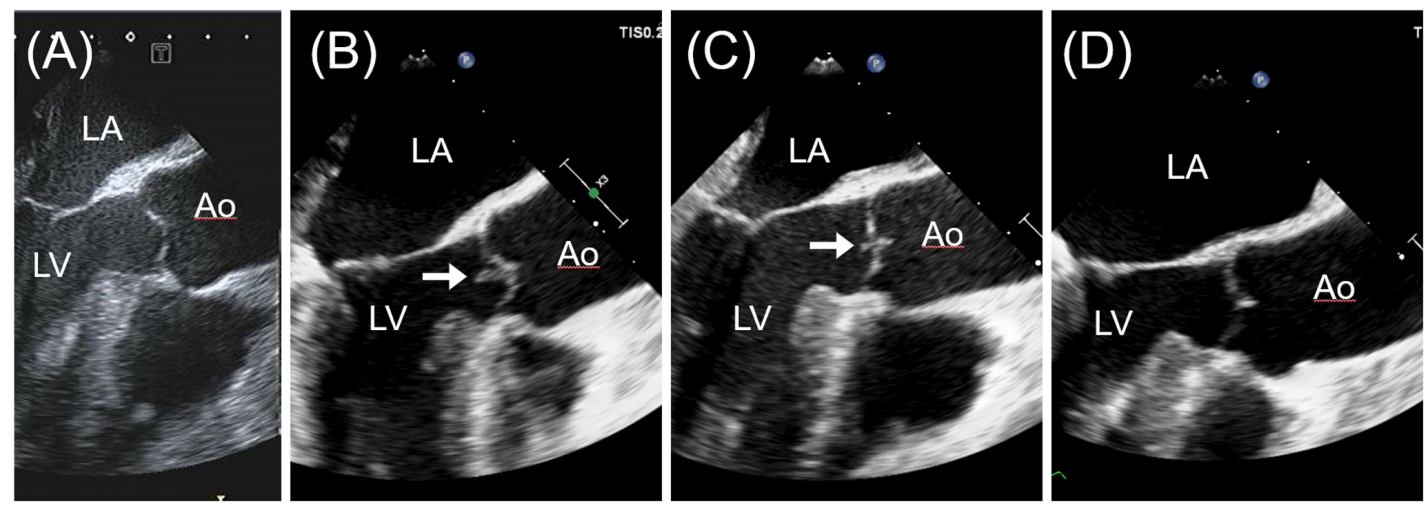

Figure 2 Transoesophageal echocardiogram in the long-axis view on admission showing no abnormality in the aortic valve (A). A vegetation (white arrows) in the aortic valve newly developed on day 25 (B), diminished rapidly within a week of initiation of heparin infusion (C) and disappeared on day 75 (D). Ao, aorta; LA, left atrium; LV, left ventricle. 
present case, the vegetation in the aortic valve developed despite treatment with apixaban and diminished drastically after the initiation of heparin infusion.

Whether direct factor $\mathrm{Xa}$ inhibitors are useful for preventing thromboembolic complications of APS is controversial, but recent studies have shown that direct oral anticoagulants are less effective than warfarin. ${ }^{34}$ Thrombin potential was less inhibited with a factor $\mathrm{Xa}$ inhibitor than with warfarin. ${ }^{5}$ This insufficiency in preventing hypercoagulability by direct factor Xa inhibitors may be associated with higher rate of thromboembolic complications in APS and may be reflected in the vegetation growth in the present case.

In conclusion, this case highlights the limited efficacy of factor Xa inhibitors for preventing thromboembolic complications of APS by demonstrating morphological changes in Libman-Sacks endocarditis under different anticoagulation regimens.

\section{Learning points}

Libman-Sacks endocarditis is a cardiac manifestation of antiphospholipid syndrome.

- Factor Xa inhibitors may be less effective for preventing thromboembolic events in Libman-Sacks endocarditis than heparin or warfarin.
Contributors TK was responsible for the conception and design of the work, as well as analysis and interpretation. TK, KS, El and KT were responsible for data collection. TK drafted the article, which was critically revised by KS, El and KT. TK, KS, $\mathrm{El}$ and $\mathrm{KT}$ were responsible for the final approval of the version to be published.

Funding The authors have not declared a specific grant for this research from any funding agency in the public, commercial or not-for-profit sectors.

Competing interests None declared.

Patient consent for publication Obtained.

Provenance and peer review Not commissioned; externally peer reviewed.

\section{REFERENCES}

1 Hojnik M, George J, Ziporen L, et al. Heart valve involvement (LibmanSacks endocarditis) in the antiphospholipid syndrome. Circulation 1996:93:1579-87

2 Agirbasli MA, Hansen DE, Byrd BF. Resolution of vegetations with anticoagulation after myocardial infarction in primary antiphospholipid syndrome. J Am Soc Echocardiogr 1997; 10:877-80.

3 Pengo V, Denas G, Zoppellaro G, et al. Rivaroxaban vs warfarin in high-risk patients with antiphospholipid syndrome. Blood 2018;132:1365-71.

4 Dufrost $V$, Risse J, Reshetnyak T, et al. Increased risk of thrombosis in antiphospholipid syndrome patients treated with direct oral anticoagulants. Results from an international patient-level data meta-analysis. Autoimmun Rev 2018;17:1011-21

5 Cohen $\mathrm{H}$, Hunt BJ, Efthymiou M, et al. Rivaroxaban versus warfarin to treat patients with thrombotic antiphospholipid syndrome, with or without systemic lupus erythematosus (RAPS): a randomised, controlled, open-label, phase 2/3, non-inferiority trial. Lancet Haematol 2016;3:e426-e436.

Copyright 2019 BMJ Publishing Group. All rights reserved. For permission to reuse any of this content visit https://www.bmj.com/company/products-services/rights-and-licensing/permissions/

BMJ Case Report Fellows may re-use this article for personal use and teaching without any further permission.

Become a Fellow of BMJ Case Reports today and you can:

- Submit as many cases as you like

Enjoy fast sympathetic peer review and rapid publication of accepted articles

- Access all the published articles

Re-use any of the published material for personal use and teaching without further permission

For information on Institutional Fellowships contact consortiasales@bmjgroup.com

Visit casereports.bmj.com for more articles like this and to become a Fellow 